\title{
Corrigendum
}

\section{Corrigendum to "Mobile Target Tracking Based on Hybrid Open-Loop Monocular Vision Motion Control Strategy"}

\author{
Cao Yuan, ${ }^{1,2,3}$ Ma Lianchuan, ${ }^{1,2,3}$ and Weigang $\mathrm{Ma}^{4}$ \\ ${ }^{1}$ National Engineering Research Center of Rail Transportation Operation and Control System, Beijing Jiaotong University, \\ Beijing 100044, China \\ ${ }^{2}$ School of Electronic and Information Engineering, Beijing Jiaotong University, Beijing 100044, China \\ ${ }^{3}$ State Key Laboratory of Rail Traffic Control and Safety, Beijing Jiaotong University, Beijing 100044, China \\ ${ }^{4}$ Faculty of Computer Science and Engineering, Xian University of Technology, Xian 710048, China \\ Correspondence should be addressed to Ma Lianchuan; malianchuan@126.com \\ Received 22 January 2016; Accepted 4 July 2016
}

Copyright (C) 2016 Cao Yuan et al. This is an open access article distributed under the Creative Commons Attribution License, which permits unrestricted use, distribution, and reproduction in any medium, provided the original work is properly cited.

In the article titled "Mobile Target Tracking Based on Hybrid Open-Loop Monocular Vision Motion Control Strategy" [1], there was an error in the "Acknowledgments" section, which should be corrected as follows.

This study was supported by the National Natural Science Foundation of China (Grants nos. 51305021, U1434203, and U1334211) and National Science and Technology support program (no. 2015BAG12B01).

\section{References}

[1] C. Yuan, M. Lianchuan, and W. Ma, "Mobile target tracking based on hybrid open-loop monocular vision motion control strategy," Discrete Dynamics in Nature and Society, vol. 2015, Article ID 690576, 10 pages, 2015. 


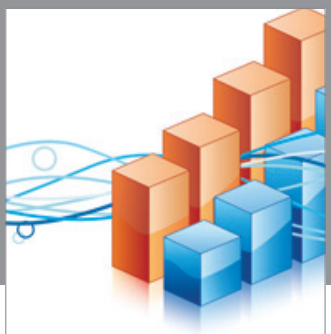

Advances in

Operations Research

vatem alat4

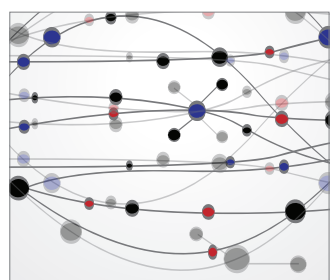

\section{The Scientific} World Journal
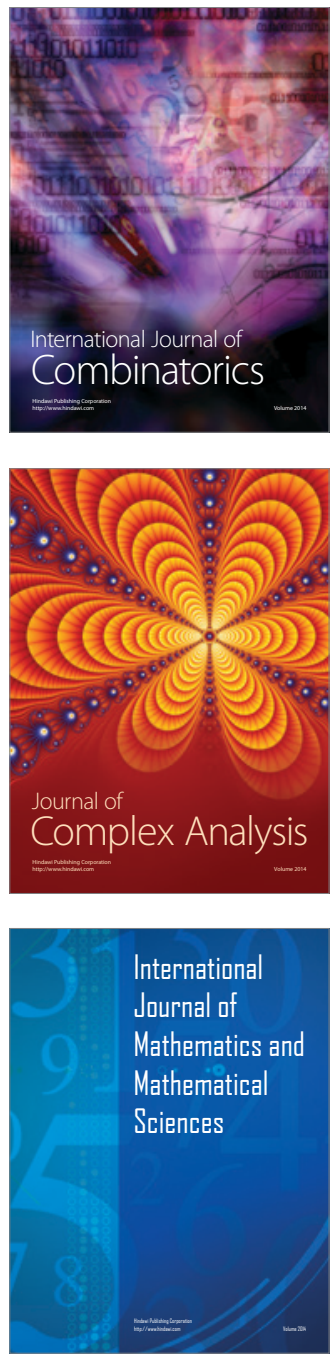
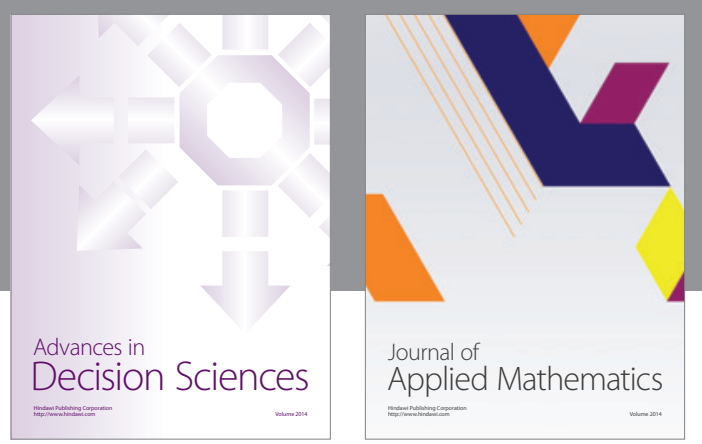

Algebra

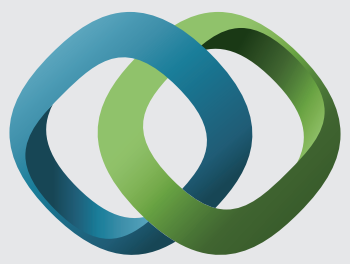

\section{Hindawi}

Submit your manuscripts at

http://www.hindawi.com
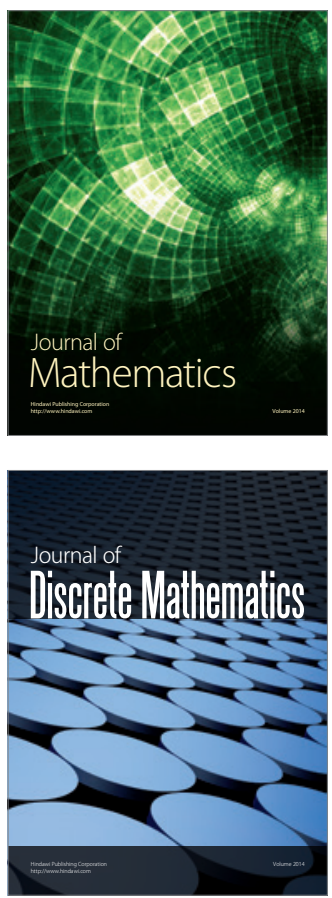

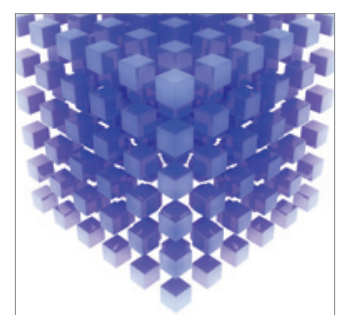

Mathematical Problems in Engineering
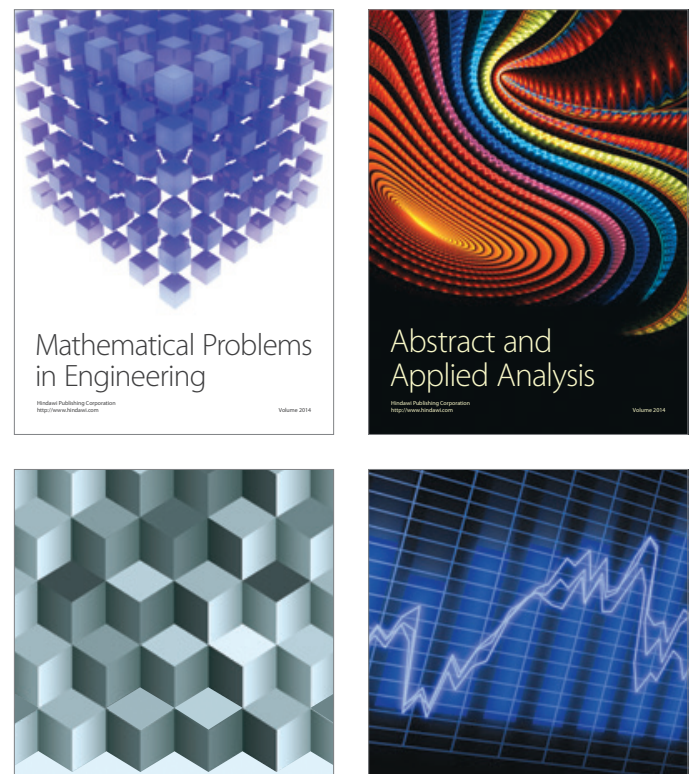

Journal of

Function Spaces

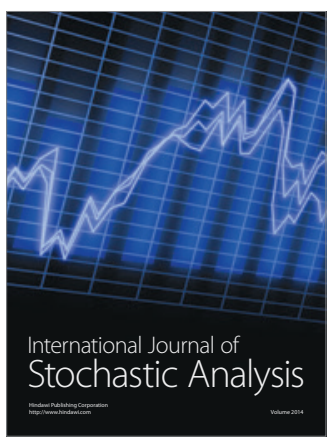

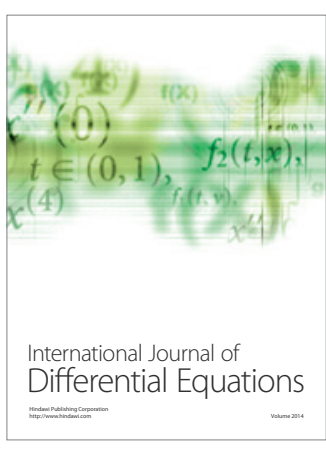
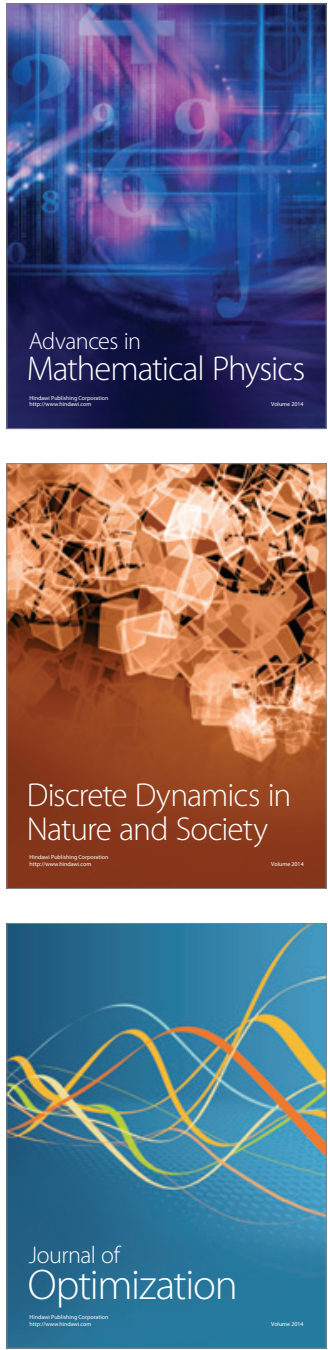